\title{
An X-Ray Diffraction Study on Crystalline and Mesomorphic Structures of Poly(diethylsiloxane)
}

\author{
Katsuhiro InOmata, ${ }^{\dagger}$ Kazami Yamamoto, and Takuhei Nose \\ Department of Polymer Chemistry, Tokyo Institute of Technology, \\ 2-12-1 Ookayama, Meguro-ku, Tokyo 152-8552, Japan
}

(Received August 15, 2000; Accepted September 8, 2000)

\begin{abstract}
Crystal structure and molecular packing analysis for crystalline and mesomorphic poly(diethylsiloxane) (PDES) have been studied by wide-angle X-Ray diffraction measurements using uniaxially-oriented PDES sample without crosslinking process. Well-oriented fiber diffraction pattern measured at $0^{\circ} \mathrm{C}$, which corresponds to the $\beta_{2}$ polymorph, can be satisfactorily indexed by monoclinic unit cell with $c$ (fiber axis) $=5.02 \AA$. Only four independent reflections can be observed for mesomorphic PDES at $26^{\circ} \mathrm{C}$, but the orientational direction of the PDES specimen has been maintained after the crystalline-mesophase transition. Molecular-packing manner of crystalline $\beta_{2}$-PDES has been estimated with assuming planar- $\mathrm{Si}-\mathrm{O}$ - backbone with alternating cis-trans conformation.

KEY WORDS Poly(diethylsiloxane) / Crystal Structure / Mesophase / X-Ray Diffraction / Polymorphism /
\end{abstract}

Poly(diethylsiloxane) (PDES) consists of a flexible inorganic backbone and organic side chains $\left[-\mathrm{Si}\left(\mathrm{CH}_{2} \mathrm{CH}_{3}\right)_{2}\right.$ $\left.{ }^{-} \mathrm{O}^{-}\right]_{m}$ and has an unique thermal properties such as formation of thermotropic mesophase without any mesogenic unit. ${ }^{1-4}$ There have been reported two crystalline polymorphs, $\alpha$ and $\beta$ for PDES, and each of them undergoes a disordering crystal-crystal transition from $\alpha_{1}$ to $\alpha_{2}$ or $\beta_{1}$ to $\beta_{2}$ at $c a .-63^{\circ} \mathrm{C}$. For high molecular weight PDES, both $\alpha_{2}$ and $\beta_{2}$ polymorphs show transition to a mesophase, $\alpha_{\mathrm{m}}$, at ca. $7^{\circ} \mathrm{C}$ and $17^{\circ} \mathrm{C}$, respectively. ${ }^{1-4}$ Solid state ${ }^{13} \mathrm{C}$ and ${ }^{29} \mathrm{Si}$ nuclear magnetic resonance (NMR) studies on PDES ${ }^{5,6}$ indicated that a jump-like motions of the side chain ethyl groups begin at the transition from the lower-temperature to the highertemperature crystalline phase. Further increase of temperature above the transition temperature for crystalline state to mesophase $\alpha_{\mathrm{m}}$ induces a large amplitude molecular motion of $-\mathrm{Si}-\mathrm{O}-$ backbone. Transition from $\alpha_{\mathrm{m}}$ to isotropic liquid occurs at $7-67^{\circ} \mathrm{C}$, strongly depends on molecular weight of PDES. ${ }^{4}$ Existence of the mesomorphic phase has also been reported for other poly(di- $n$-alkylsiloxane)s (PDAS) $\left[-\mathrm{Si}\left(\mathrm{C}_{n} \mathrm{H}_{2 n+1}\right)_{2}-\mathrm{O}^{-}\right]_{m}$ of higher homologues with $n=2-6$ and poly(diphenylsiloxane) ${ }^{3,7}$ Because of the conformational disorder of $-\mathrm{Si}-\mathrm{O}-$ backbone, this mesophase has been described as conformational disordered (Condis) crystal. ${ }^{8,9}$ However, the origin of the mesophase formation for these flexible polymers has not entirely been clarified yet. Recent differential scanning calorimetry (DSC) and transmission electron microscopy (TEM) study for PDES with narrowmolecular-weight distribution by Molenberg et $a l^{4}{ }^{4}$ showed an existence of extended chain lamellae in $\beta$ - and $\alpha_{\mathrm{m}}$ PDES.

Some structural investigations for di-substituted polysiloxanes by means of X-Ray analysis have been re-

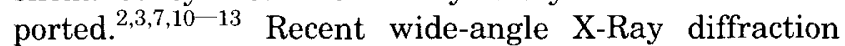
(WAXD) analysis by using X-Ray fiber patters for silicafilled poly(dimethylsiloxane) rubber reported that the backbone conformation is four-fold helix. ${ }^{10}$ Tsvankin et al. performed WAXD measurements for stretched crosslinked PDES films within the temperature range of crystalline and mesomorphic state, prepared by peroxide vulcanization. ${ }^{2,3}$ From the fiber patters, they determined unit cell parameters for modifications of $\alpha_{1}, \alpha_{2}$, and $\alpha_{\mathrm{m}}$. The identity period for the fiber axis was $4.72,4.75$, and $4.90 \AA$, respectively, and they suggested the cis-trans conformation for the backbone from geometrical consideration. ${ }^{2}$ The conformational stability for the planar backbone is also examined by molecular mechanics calculation of isolated PDES chain by Miller et al. ${ }^{14} \mathrm{By}$ combined use of molecular modeling method and X-Ray powder diffraction pattern, Grigoras et al. investigated structure analysis of crystalline poly (diphenylsiloxane). ${ }^{13}$ The backbone conformation is determined as quasi cis-trans conformation, which is same as the proposed conformation for PDES. For other homologues of PDAS, only the $\mathrm{X}$-Ray powder diffraction patterns and limited results of structural analysis have been reported.

In this study, we have successfully obtained WAXD fiber pattern for the well-oriented non-crosslinked PDES specimen in crystalline and mesomorphic state. Comparison with the powder diffraction patterns for PDES by Tsvankin et al., ${ }^{2}$ our oriented sample has been determined as $\beta_{2^{-}}$and $\alpha_{\mathrm{m}}$-PDES. From the fiber diffractogram for $\beta_{2}$-PDES, crystal structure analysis has been performed by linked-atom least squares method.

\section{EXPERIMENTAL}

High molecular weight PDES was prepared by ringopening polymerization of hexaethyltrisiloxane. ${ }^{15,16}$ Crude PDES sample was repeatedly fractionated using mixed solvent of chloroform/methanol. The molecular weight and molecular-weight distribution index determined by size-exclusion chromatography (standard polystyrene and tetrahydrofurane as eluent were used) were

\footnotetext{
${ }^{\dagger}$ To whom correspondence should be addressed (Phone: +81-3-5734-2632, Fax: +81-3-5734-2888, E-mail: kinomata@polymer.titech.ac.jp).
} 


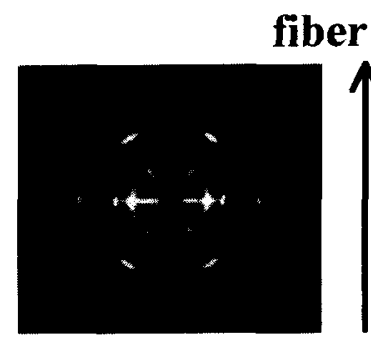

(a)

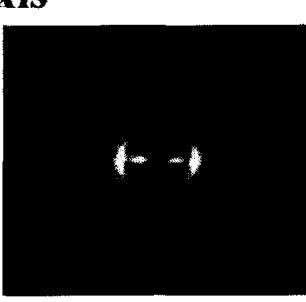

(b)
Figure 1. X-Ray fiber diagrams of PDES observed at the temperature of $0^{\circ} \mathrm{C}(\mathrm{a})$ and $26^{\circ} \mathrm{C}(\mathrm{b})$.

$M_{\mathrm{w}}=205000$ and $M_{\mathrm{w}} / M_{\mathrm{n}}=1.52$, respectively. The value of $M_{\mathrm{w}}$ is higher than the critical molecular weight for mesophase formation for PDES $\left(M_{\mathrm{n}}=28000\right)$ reported in ref 4. Uniaxially-oriented PDES in non-crosslinked state was prepared as follows: PDES sample quenched from molten state $\left(\mathrm{ca} .80^{\circ} \mathrm{C}\right)$ into liquid nitrogen was placed in room-temperature condition, and stretched after the glassy PDES became soft above its glass transition temperature $\left(T_{\mathrm{g}}\right)$. Thus stretched PDES specimen was kept in liquid nitrogen until WAXD measurement.

WAXD measurements were performed using $\mathrm{Ni}$ filtered $\mathrm{Cu}-K_{\alpha}$ radiation generated by $\mathrm{RU}-200 \mathrm{BH}$ (Rigaku). Diffracted X-Ray was recorded on a flat imaging plate detector (RAXIS IID, Rigaku). The stretched PDES sample was placed as the incident X-Ray beam being normal to the fiber axis. There were $950 \times 950$ pixels in the imaging plate, and size of the pixel was $0.21 \times 0.21$ $\mathrm{mm}^{2}$. The reflection spacings were calibrated against the 111 reflection of silicon powder. For low-temperature WAXD measurements, the sample was cooled in a flow of liquid nitrogen vapor. The sample temperature was regulated within $\pm 1^{\circ} \mathrm{C}$. The WAXD measurement was started from the lower temperature in crystalline state, and the temperature was slowly increased above the temperature of crystalline-mesophase transition. However, above the mesophase-isotropic transition temperature $\left(55^{\circ} \mathrm{C}\right)$, the specimen became fluid-like, and the orientation of fiber axis was lost. Reflection intensities were collected by a procedure of integration as described in the previous report. ${ }^{17}$ Structure amplitudes were obtained after Lorentz-polarization correction corresponding to the normal-beam method for single crystal. ${ }^{18,19}$ The density of the stretched sample was determined by floatation method in aqueous solution of potassium bromide. Structure refinement was performed by the fullmatrix linked-atom least squares method using a computer program developed by S. Sasaki at Japan Advanced Institute of Science and Technology, in which torsion angles of the chains can be refined with the fixed values of bond lengths and bond angles.

\section{RESULTS AND DISCUSSION}

Wide-angle X-Ray fiber diagrams of the oriented PDES measured at $0{ }^{\circ} \mathrm{C}$ and $26^{\circ} \mathrm{C}$ are shown in Figures $1 \mathrm{a}$ and $1 \mathrm{~b}$, respectively. DSC results for PDES indicate that these temperatures correspond to the crystalline and mesomorphic state, respectively, because the transition temperature from crystalline phase to mesophase is about $7^{\circ} \mathrm{C}$. As noted in the introduction, Tsvankin et al. ${ }^{2}$ reported X-Ray fiber photographs of a crosslinked oriented PDES sample, and determined the unit cell parameters of $\alpha$ polymorph. WAXD profiles for noncrosslinked non-oriented PDES samples were used to identify the reflections for $\beta$ polymorph. Although our PDES was not crosslinked, the WAXD patterns in Figure 1 indicate that the sample is highly oriented at $0^{\circ} \mathrm{C}$, and the orientational direction is maintained after the transition from crystalline to mesomorphic state at $26^{\circ} \mathrm{C}$. Comparison of our result with Tsvankin et al.'s WAXD patterns ${ }^{2}$ tells us that the diffractogram in Figure 1a can be assigned to the $\beta_{2}$ modification, that is, some reflections for $\alpha$-PDES ( $d=7.03 \AA$ and $4.35 \AA$ ) are not recognized and reflection for $\beta$-PDES of $d=5.66 \AA$ is observed on equatorial line in Figure 1a.

All the 34 independent reflections in Figure 1a can be indexed satisfactorily by monoclinic unit cell. The cell dimensions were refined by least-square method and are listed in Table I with the observed and calculated densities. The calculated density for the crystalline cell suggests that the unit cell contains two monomer units of PDES. The fiber identity period $(c=5.02 \AA)$ corresponds to the planar cis-trans-cis-trans conformation for - $\mathrm{Si}-\mathrm{O}$ $\mathrm{Si}-\mathrm{O}^{-}$- backbone, as pointed out by Tsvankin et al. ${ }^{2}$ Small difference between the observed and calculated densities shown in Table I suggests that our oriented PDES sample is highly crystallized. Observed $\left(d_{\text {obs }}\right)$ and calculated $\left(d_{\text {calc }}\right)$ spacings are compared in Table II. For comparison, the unit cell parameters of the previously published PDES polymorphs ${ }^{3}$ are also shown in Table I. In ref 2 and 3 , the $\beta_{2}$-PDES is estimated as a tetragonal unit cell, ${ }^{2}$ however, the cell parameters for $\beta$ polymorph were determined by using the powder diffractgram of nonoriented samples.

With the increase of temperature, the crystalline reflections decrease in intensity, and completely disappear at $26^{\circ} \mathrm{C}$ as seen in Figure $1 \mathrm{~b}$. This temperature corresponds to the mesomorphic state. Only four independent reflections were observed in WAXD pattern for the mesophase PDES. The cell parameters evaluated from these reflections with assuming hexagonal lattice was not reasonable because of the inconsistency of observed and calculated density $\left(0.99\right.$ and $0.94 \mathrm{~g} \mathrm{~cm}^{-3}$, respectively). In Table I, the refined unit cell parameters obtained with assuming monoclinic lattice are indicated. The calculated density for this monoclinic cell is larger than the observed one on the assumption that the unit cell contains two monomer units. The change in $c$ dimension at the transition from crystalline phase to mesophase is relatively small, i.e., from $5.02 \AA$ in crystalline state to $4.91 \mathrm{~A}$ in mesophase.

The list of the $h k l$ indices for the observed reflections in Table II suggests that $h 0 l$ reflections with odd value of $l(=1)$ are not observed. The cis-trans conformation of the main chain satisfies the presence of glide plane parallel to the molecular axis and perpendicular to the planar backbone. From these considerations, the space group for this crystalline form is evaluated as $P c-C^{2} s$ which shows the systematic absences of $l \neq 2 n$ for $h 0 l$ reflections, ${ }^{20}$ and the planar backbone with alternating cis-trans conformation is assumed to go through the unit cell with the backbone plane being parallel to $b c$ plane. 
K. INOMATA, K. Yamamoto, and T. Nose

Table I. Comparison of determined and published unit cell parameters of PDES polymorphs

\begin{tabular}{|c|c|c|c|c|c|}
\hline & $\beta_{2}{ }^{a}$ & $\alpha_{\mathrm{m}}^{\mathrm{a}}$ & $\alpha_{2}^{b}$ & $\beta_{2}^{\mathbf{b}}$ & $\alpha_{\mathrm{m}}^{\mathrm{b}}$ \\
\hline$a / \AA$ & $8.32(6)$ & 8.39 & 8.15 & 7.90 & 8.51 \\
\hline$b / \AA$ & $8.12(8)$ & 8.77 & 8.90 & 7.90 & 8.89 \\
\hline$c / \AA$ & $5.02(2)$ & 4.91 & 4.75 & 4.72 & 4.88 \\
\hline$\alpha /$ degree & 90.0 & 90.0 & 90.0 & 90.0 & 90.0 \\
\hline$\beta /$ degree & $108.0(3)$ & 90.0 & 90.0 & 90.0 & 90.0 \\
\hline$\gamma /$ degree & 90.0 & 65.2 & $62.3(6)$ & 90.0 & 64.06 \\
\hline Calc'd density/g $\mathrm{cm}^{-3}$ & 1.05 & 1.01 & 1.10 & 1.14 & 1.02 \\
\hline Space group & $P c-C^{2} s$ & & & & \\
\hline
\end{tabular}

${ }^{a}$ This work. ${ }^{\mathrm{b}} \operatorname{Ref} 3$.

Table II. Comparison between observed and calculated $d$-spacings and structure factors of the $\beta_{2}$ polymorph ${ }^{a}$

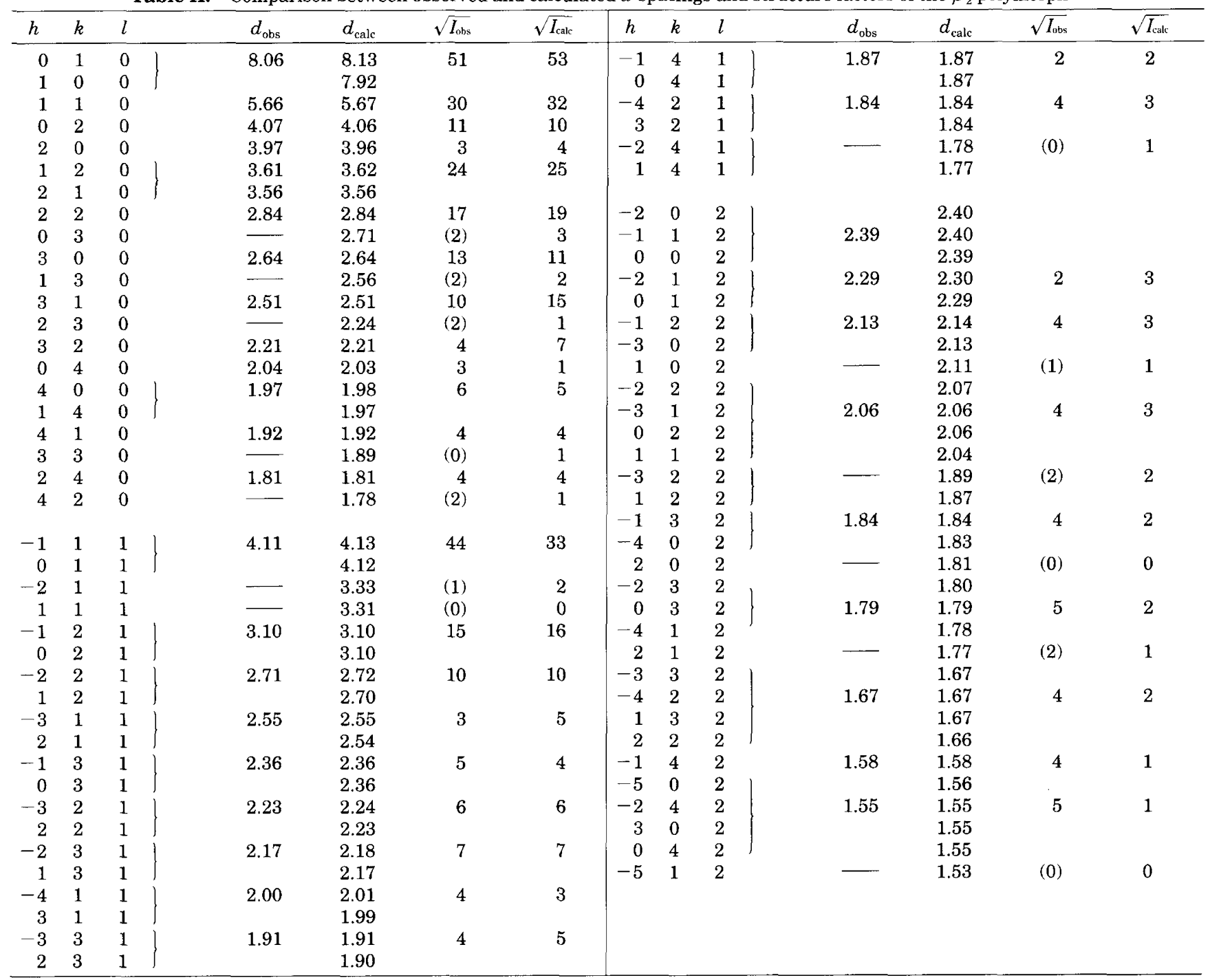

${ }^{\mathrm{a}} \sqrt{I_{\mathrm{ubs}}}$ values in parentheses are unobserved ones.

Molecular models were built on the basis of the standard bond lengths and bond angles listed in Table III. Because of the large difference between the bond angle of $\mathrm{O}-\mathrm{Si}-\mathrm{O}\left(109.47^{\circ}\right)$ and $\mathrm{Si}-\mathrm{O}-\mathrm{Si}\left(141.25^{\circ}\right)$, it is impossible to form a trans zigzag conformation in crystalline state. Structure refinement was performed by the linked-atom least-squares method with the fixed bond lengths and bond angles as the prescribed values.

In addition to the 32 observed independent reflections, 13 unobserved reflections were taken into account by as- suming zero intensity or the half of the observational intensity threshold. As mentioned above, the conformation of the backbone was fixed at cis $\left(0^{\circ}\right)$ or trans $\left(180^{\circ}\right)$ state, and the planar molecular chain was placed as being coincident with the $b c$ plane. Therefore, the refined parameters were two torsion angles for $\mathrm{Si}-\mathrm{CH}_{2}$ bond $(\mathrm{Si}-\mathrm{C}$ (1) and $\mathrm{Si}-\mathrm{C}(3)$ ) in the unique monomer unit, an overall isotropic temperature factor $B$, and a scale factor.

The refined crystal structure is illustrated in Figure 2, and the calculated structure factor $\left(\sqrt{I_{\text {calc }}}\right)$ is compared 
Table III. Geometrical parameters

\begin{tabular}{cccc}
\hline Bond & Length/A & Bond angle & Angle/degree \\
\hline $\mathrm{Si}-\mathrm{O}$ & 1.630 & $\mathrm{Si}-\mathrm{O}-\mathrm{Si}$ & 141.25 \\
$\mathrm{Si}-\mathrm{C}$ & 1.867 & $\mathrm{O}-\mathrm{Si}-\mathrm{O}$ & 109.47 \\
$\mathrm{C}-\mathrm{C}$ & 1.540 & $\mathrm{O}-\mathrm{Si}-\mathrm{C}$ & 109.47 \\
$\mathrm{C}-\mathrm{H}$ & 1.100 & $\mathrm{Si}-\mathrm{C}-\mathrm{H}$ & 109.47 \\
& & $\mathrm{C}-\mathrm{C}-\mathrm{H}$ & 109.47 \\
\hline
\end{tabular}

c
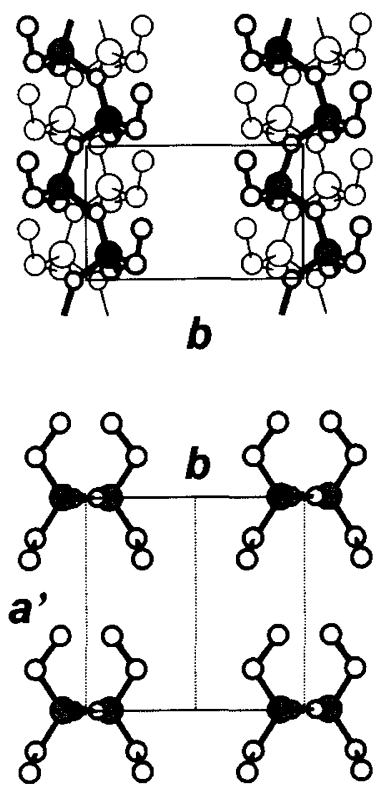

Figure 2. Arrangement of molecules in $\beta_{2}$ polymorph at $0^{\circ} \mathrm{C}$ Above, projection on the $b c$ plane; below, projection along the $c$ axis.

with the observed one $\left(\sqrt{I_{\mathrm{obs}}}\right)$ in Table II. The packing manner of $\beta_{2}$-PDES as seen in the projection on the $b c$ plane in Figure 2 indicates that the neighboring chains along the $a$-direction are shifted in the opposite direction to each other by about one monomer unit along the $c$ axis, i.e., $a \cos \beta \cong c / 2$. This packing manner seems reasonable to avoid the steric interaction between the side chains in neighboring PDES chains, and there were no abnormally close contacts in interchain atomic distance in the refined structure. The discrepancy factor $R=\Sigma$ $\left|\sqrt{I_{\mathrm{obs}}}-\sqrt{I_{\text {calc }}}\right| / \Sigma \sqrt{I_{\mathrm{obs}}}$ was 0.205 for the total intensity data. The final value of the overall isotropic temperature factor $B$ was $28 \AA^{2}$, which is rather large as compared to that of the other usual crystalline polymers at room temperature $\left(B=5-10 \AA^{2}\right)$. This should be related to the dynamical motion of $\beta_{2}$-PDES as mentioned in the introduction. The values of two torsion angles for $-\mathrm{O}-\mathrm{Si}+\mathrm{C}$ (1) $\mathrm{H}_{2}-\mathrm{C}(2) \mathrm{H}_{3}$ and $-\mathrm{O}-\mathrm{Si}-\mathrm{C}(3) \mathrm{H}_{2}-\mathrm{C}(4) \mathrm{H}_{3}$ were refined as $124^{\circ}$ and $-40^{\circ}$, respectively. The most probable fractional atomic coordinates are shown in Table IV. It should be noticed again that the dynamical jump-like motion for ethyl side chains is reported to occur in $\beta_{2^{-}}$ PDES as the fact that only two signals were observed in MAS ${ }^{13} \mathrm{C}$ NMR spectrum for $\beta_{2}$-PDES. ${ }^{5}$ Therefore, the finally refined structure for the side chains, i.e., the positions of the methyl groups depicted in Figure 2, should be the averaged one. Molecular dynamics simulations for crystalline PDES at various temperatures, which will give valuable information for the dynamic motion of side
Table IV. Fractional atomic coordinates for the $\beta_{2}$ polymorph of PDES at $0^{\circ} \mathrm{C}$

\begin{tabular}{lrrc}
\hline Atom & \multicolumn{1}{c}{$x$} & \multicolumn{1}{c}{$y$} & $z$ \\
\hline $\mathrm{O}$ & 0.000 & -0.054 & 0.000 \\
$\mathrm{Si}$ & 0.000 & 0.109 & 0.188 \\
$\mathrm{C}(1)$ & -0.193 & 0.234 & 0.018 \\
$\mathrm{C}(2)$ & -0.292 & 0.261 & 0.226 \\
$\mathrm{C}(3)$ & 0.193 & 0.234 & 0.215 \\
$\mathrm{C}(4)$ & 0.344 & 0.119 & 0.247 \\
\hline
\end{tabular}

chains, are in progress.

There has been reported that the $\beta$-PDES is formed by slow cooling from the mesomorphic $\alpha_{\mathrm{m}}$ state, whereas a high fraction of $\alpha$ polymorph can be attained by rapid cooling from the melt. ${ }^{2-4}$ It should be noticed that we have obtained the oriented $\beta_{2}$ polymorph by stretching the amorphous non-crosslinked PDES, which was rapidly quenched from the melt. For $\beta$ and $\alpha_{\mathrm{m}}$ polymorphs, the existence of extended chain lamellae was pointed out by DSC and TEM. ${ }^{4}$ On the other hand, less ordered packing with chain ends incorporated into the lamellae was proposed for the $\alpha$-PDES. ${ }^{4}$ From these results, we may suppose that the extended chain in $\beta$ and $\alpha_{\mathrm{m}}$ is readily achieved at temperature enough higher than $T_{\mathrm{g}}$, while the less ordered packing of $\alpha$-PDES is the result of crystallization from the amorphous state at low temperature near $T_{\mathrm{g}}$, since the chain motions at the low temperature should be restricted. Although our PDES sample was crystallized at the temperature near $T_{\mathrm{g}}$, the shear given in the stretching process may make it possible to form the extended chain crystal. In the crosslinked sample by Tsvankin et al., ${ }^{2}$ the presence of crosslinking points may prohibit the PDES molecule from forming the extended chain structure, resulting in the formation of $\alpha$-PDES.

\section{CONCLUSIONS}

X-Ray fiber diagrams for well-oriented samples of noncrosslinked crystalline and mesomorphic PDES have been obtained. Fiber diffraction pattern measured at 0 ${ }^{\circ} \mathrm{C}$, which is compared with $\beta_{2}$ polymorph by Tsvankin et $a l .{ }^{2}$ can be satisfactorily indexed by monoclinic unit cell with $c$ (fiber axis) $=5.02 \AA$. Packing manner analysis has been performed for the crystalline PDES with assuming the alternating cis-trans conformation for $-\mathrm{Si}-\mathrm{O}-$ backbone. The orientational direction in crystalline state has been maintained after the crystalline-mesophase transition even in the non-crosslinked PDES. Formation of $\beta$ polymorph by stretching the rapidly quenched sample is in contrast with the usual observation that $\alpha$-PDES is crystallized in the rapidly quenched PDES without any external stress. The stretching process applied when crystallization occurs near $T_{\mathrm{g}}$ is proposed to be the reason for the formation of $\beta$-PDES.

Acknowledgment. The authors thank Professor Shoei Fujisige at Tokyo Kasei University for kindly providing the poly(diethylsiloxane) used in this study. We greatly thank Professor Shintaro Sasaki at Japan Advanced Institute of Science and Technology for providing the computer program for the linked-atom least-square refinement of crystal structure. 


\section{REFERENCES}

1. V. S. Papkov, Yu. K. Godovsky, V. S. Svistunov, V. M. Litvinov, and A. A. Zhdanov, J. Polym. Sci., Polym. Chem. Ed., 22, 3617 (1984).

2. D. Ya. Tsvankin, V. S. Papkov, V. P. Zhukov, Yu. K. Godovski, V. S. Svistunov, and A. A. Zhdanov, J. Polym. Sci., Polym. Chem. Ed., 23, 1043 (1985).

3. Yu. K. Godovsky and V. S. Papkov, Adv. Polym. Sci., 88, 129 (1989).

4. A. Molenberg and M. Möller, Macromolecules, 30, 8332 (1997).

5. G. Kögler, A. Hasenhindl, and M. Möller, Macromolecules, 22, 4190 (1989).

6. G. Kögler, K. Loufakis, and M. Möller, Polymer, 31, 1538 (1990).

7. G. J. J. Out, A. A. Turetskii, M. Möller, and D. Oelfin, Macromolecules, 27, 3310 (1994).

8. B. Wunderlich and J. Grebowicz, Adv. Polym. Sci., 60/61, 1 (1984).

9. B. Wunderlich, M. Möller, J. Grebowicz, and H. Baur, Adv. Polym. Sci., 87, 1 (1988).

10. P.-A. Albouy, Polymer, 41, 3083 (2000).
11. D. R. Petersen, D. R. Carter, and C. L. Lee, J. Macromol. Sci., Phys., B3, 519 (1969).

12. A. Turetskii, G. J. J. Out, H.-A. Klok, and M. Möller, Polymer, 36, 1303 (1995).

13. S. Grigoras, C. Qian, C. Crowder, B. Harkness, and I. Mita, Macromolecules, 28, 7370 (1995).

14. K. J. Miller, J. Grebowicz, J. P. Wesson, and B. Wunderlich, Macromolecules, 23, 849 (1990).

15. J. R. Brewer, K. Tsuchihara, R. Morita, J. R. Jones, J. P. Bloxsidge, S. Kagao, T. Otsuki, and S. Fujishige, Polymer, 35, 5109 (1994).

16. J. R. Brewer, K. Tsuchihara, R. Morita, J. R. Jones, J. P. Bloxsidge, and S. Fujishige, Polymer, 35, 5118 (1994).

17. K. Inomata and S. Sasaki, J. Polym. Sci., Part B: Polym. Phys., 34, 83 (1996).

18. J. S. Kasper and K. Lonsdale, Ed., "International Tables for X-ray Crystallography", Vol. II, Kynoch Press, Birmingham, 1959.

19. D. Meader, E. D. T. Atkins, M. Elder, P. A. Machin, and M. Pickering, in "Fiber Diffraction Methods", A. D. French and K. H. Gardner, Ed., ACS Symposium Series, No. 141, Washington, DC, 1980, p 113.

20. N. F. M. Henry and K. Lonsdale, Ed., "International Tables for X-Ray Crystallography", Vol. I, Kynoch Press, Birming ham, 1969. 